\title{
Development trends of tafoni forms (incipient stages)
}

\author{
DE UÑA ÁLVAREZ, E ${ }^{1}$
}

(1) Area: Physical Geography. University of Vigo.Research Group (GEAAT): Archaeology, Antiquity,Territory.Campus As Lagoas - 32004 Ourense. edeuna@uvigo.es

https://doi.org/10.17979/cadlaxe.2013.37.0.3582

\begin{abstract}
Forms called tafoni, diversified in different stages, are complex natural systems. The systematic register of their measurements is performed in order to infer relative ages and to use the results to reconstruct landscape evolution. The analysis of depth measures of the cavities developed into several tafoni demonstrates, for incipient cases in Galicia (NW of Iberian Peninsula), trends with different evolutionary trajectories. Depth measures were processed with robust statistical techniques. The development of tafoni combines linear and non-linear phases. This behaviour is related to the increase of complexity through self-organisation.
\end{abstract}

Key words: Tafoni; Galicia: development 


\section{RESEARCH FRAMEWORK}

Tafoni are small caves frequently developed in granitic rocks. Their interpretation has created a range of nominal categories defined by morphological and dimensional features. These forms are usually basal and lateral hollows on the undersides of blocks, boulders and sheet structures extended upwards into the rock mass (TWIDALE \& BOURNE, 2008). The debate remained about the definition of the cause, either physical or chemical, and about configuration controls, their age and evolution.

Tafoni show a size range from several centimetres to several metres with diverse opening plane shape (spherical, hemispherical, elliptical or irregular). The most common features of these cavities in granite terrains are cross-section in arch shape; their inner walls may be regular, flaked, honeycombed, ribbed or scalloped (TWIDALE \& VIDAL, 2005). The features of morphological design and the dimensions are related to the starting control of the generative fields.

This work has been developed in a sector of Galicia (NW of Iberian Peninsula). The rock basement is granite and granodiorite. The analysis is oriented towards variabil- ity patterns in the development of the inner walls. The systematic register of the depth of cavities into several tafoni demonstrates the behaviour of their development with different evolutionary trajectories for the cases in Galicia. This approach provided results about morphological diversity (DE UÑA, 2004; DE UÑA \& VIDAL, 2008). Tendencies towards regularity or irregularity are outlined.

\section{STUDY AREA}

Field data were recorded for several cases developed in two locations (Fig. 1). This study only displays the results for selected cases. First sample comes from Os Castelos (20-160 m a.s.1.) in the Coruña massif and second sample comes from Vilar-Mende (180-480 $\mathrm{m}$ a.s.1.) in the Ourense massif. All the tafoni are active forms in development. The host rocks are not moved or split.

The position of these cavities is always upon the edge of the granitic intrusion. Types were assigned according to the position of an initial discontinuity plane of growth in their host unity. Basal type defines forms developed beneath boulders or blocks. Sidewall type defines forms developed in quite sloped surfaces of rock. 

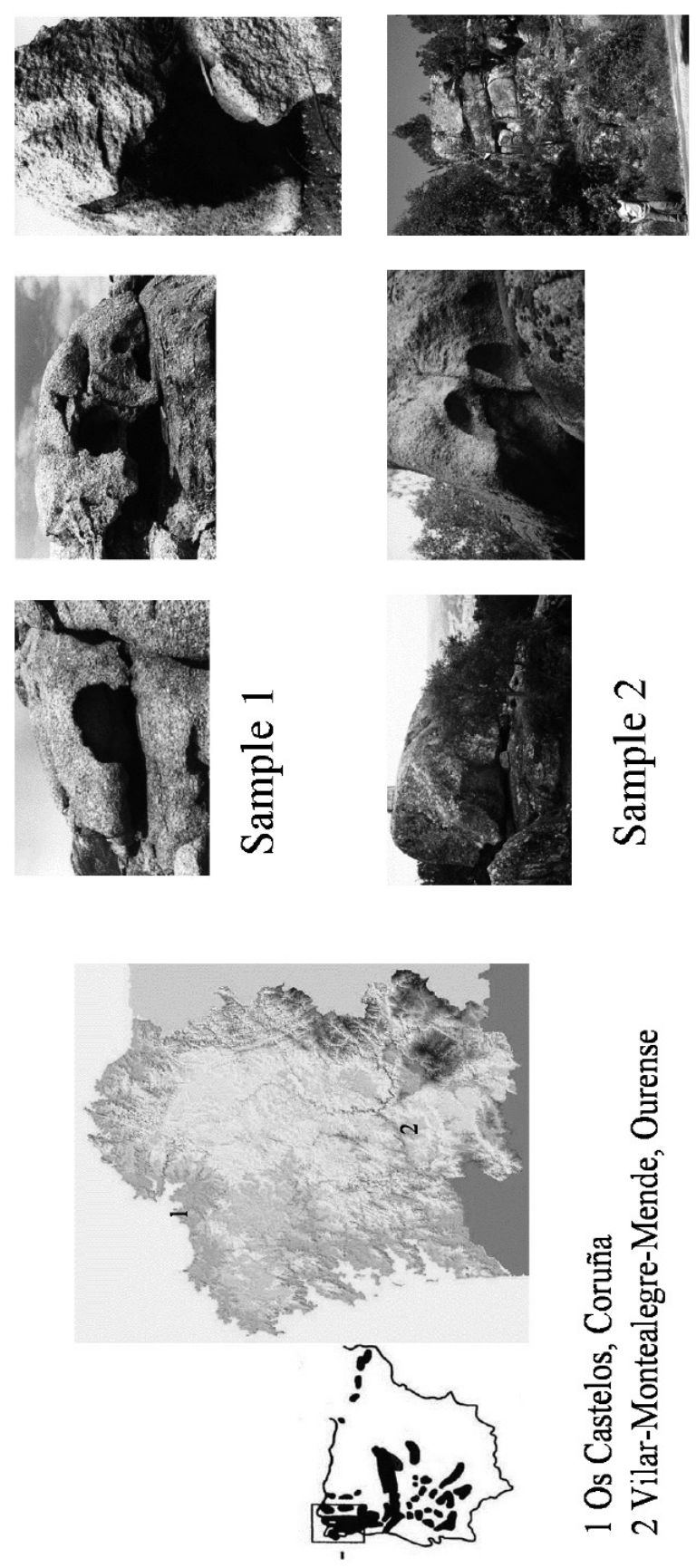

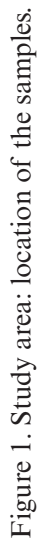




\section{ANALYSIS}

In order to typify the growth stage of each tafoni, the selected measures are the maximum depth of each cavity inside the main hollow (Table 1). This depth measure (cm) is the value of the vertical axis inside a cavity (Fig. 2). Minimum number of the inner cavities in the samples is three; maximum number of the inner cavities in the samples is twelve. All depth data have been processed with statistics techniques. These techniques have an instrumental value, as they discriminate between possibilities of permanence, transition or change in the tafoni development.

Table 1. Selected cases (tafoni)

\begin{tabular}{|c|c|c|c|c|c|}
\hline Type & Location & Position* & D1 & IC & D2 \\
\hline $\begin{array}{c}\text { Basal } \\
\mathrm{a} \\
\mathrm{b} \\
\mathrm{c}\end{array}$ & $\begin{array}{c}\text { Mende } \\
\text { Vilar } \\
\text { Castelos }\end{array}$ & $\begin{array}{r}250 \mathrm{~m} \\
480 \mathrm{~m} \\
20 \mathrm{~m}\end{array}$ & $\begin{array}{r}16 \\
130 \\
100\end{array}$ & $\begin{array}{l}4 \\
9 \\
5\end{array}$ & $\begin{array}{l}14 \\
70 \\
68\end{array}$ \\
\hline $\begin{array}{c}\text { Side-wall } \\
\text { a } \\
\text { b } \\
\text { c }\end{array}$ & $\begin{array}{l}\text { Mende } \\
\text { Mende } \\
\text { Castelos }\end{array}$ & $\begin{array}{l}190 \mathrm{~m} \\
180 \mathrm{~m} \\
160 \mathrm{~m}\end{array}$ & $\begin{array}{r}15 \\
60 \\
200\end{array}$ & $\begin{array}{r}3 \\
12 \\
5\end{array}$ & $\begin{array}{l}14 \\
52 \\
70\end{array}$ \\
\hline
\end{tabular}

$* \mathrm{~m}$ a.s.l. D1 = Maximum depth in basal and side-wall forms $(\mathrm{cm}) . \mathrm{IC}=$ Number of inner cavities. D2 $=$ Maximum depth of the inner cavities (cm).

Research results provide the trends in the inner diversification of the tafoni throughout their development. Multiple states in continuous change are presented where growth in depth reveals cascade sequences of creation, persistence, or transformation related to critical configurations. Previous studies in this area (DE UÑA \& VIDAL, 2006) prove that the opening of the tafoni is a self-reinforcing process starting from a discontinuity plane. Their shape is usually a circle or an ellipse, with strong positive correlation between the measures of the length and the width (Spearman coefficient $>0.90$ ). However, the trends of growth in depth may be different. The statistical analysis of their values allows understanding it.
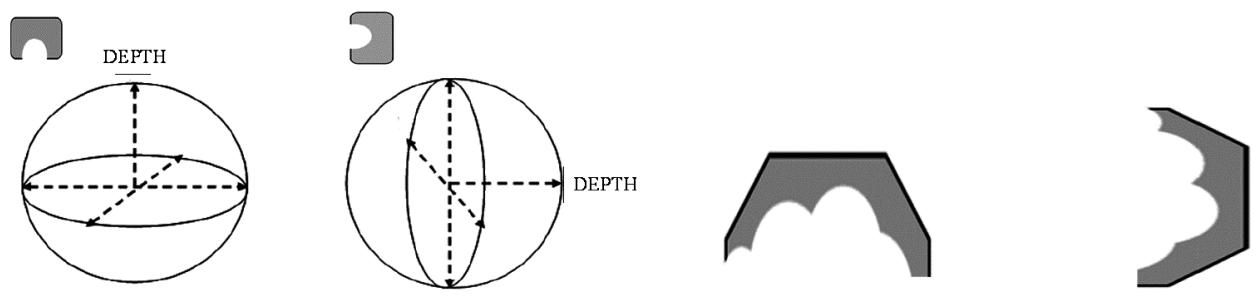

Figure 2. Depth measures from main cavity (left), inner cavities (right). 
First stage of analysis has an exploratory character. Box-plots from depth cavities in the selected tafoni (Fig. 3) reveal three possible conditions. Very incipient development (a), in basal and side-wall forms, has similar values (maximum depth $<20 \mathrm{~cm}$ ). The median depth in the inner cavities of these forms is related to the median value that results for moderate development (b),

a

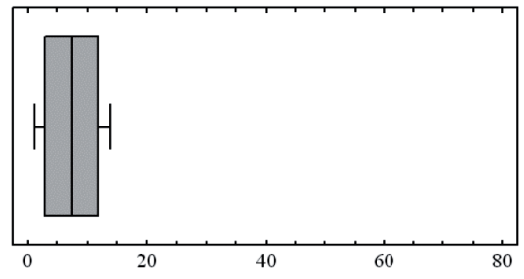

b

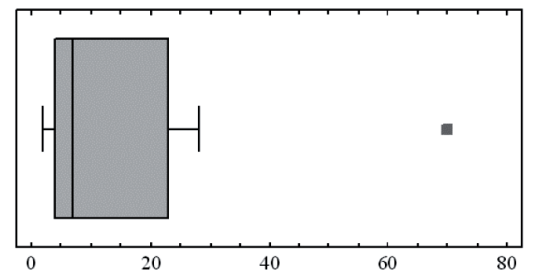

c

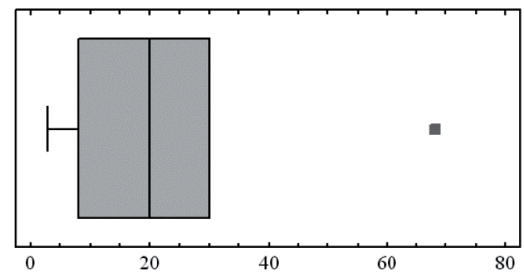

Depth of cavities (cm): basal forms (a \& b sample 2; c, sample 1) but maximum values and outliers are here moved away. Transition from (a) to (b) supposes an increase in the number of hollows into the main cavity. The upper limit of nooutlier data in the intermediate growth is close to the median depth of cavities developed inside the biggest forms (c). Transition from (b) to (c) supposes a drop in the number of hollows into the main cavity.
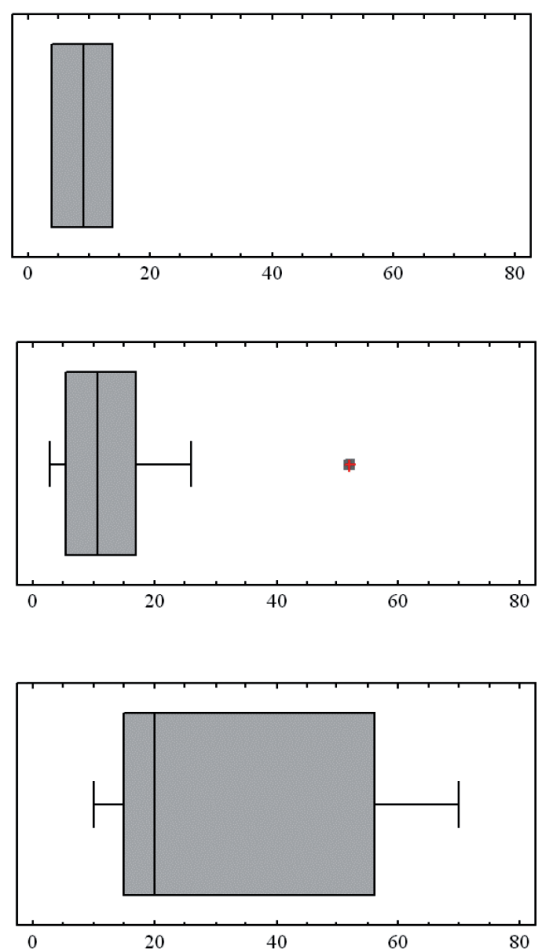

Depth of cavities $(\mathrm{cm})$ : lateral forms (a \& b sample 2; c, sample 1)

Figure 3. Box plots (depth of cavities in $\mathrm{cm}$ ). 
Second stage of analysis searches the trends and the steps in the data distribution (Fig. $4 \& 5$ ). The quantile plots display the growth phases in the tafoni development. The probability plots display their trends by the fittest for the data distribution (normal, lognormal). The growth rate slows down when the form size and complexity increase, regardless of the spatial-temporal scale subject to consideration. The development of the form combines linear and no-linear phases. The linear trend is always related to the start

QUANTILE PLOT (Growth)

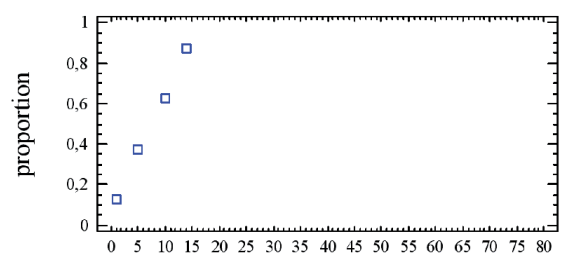

Mende
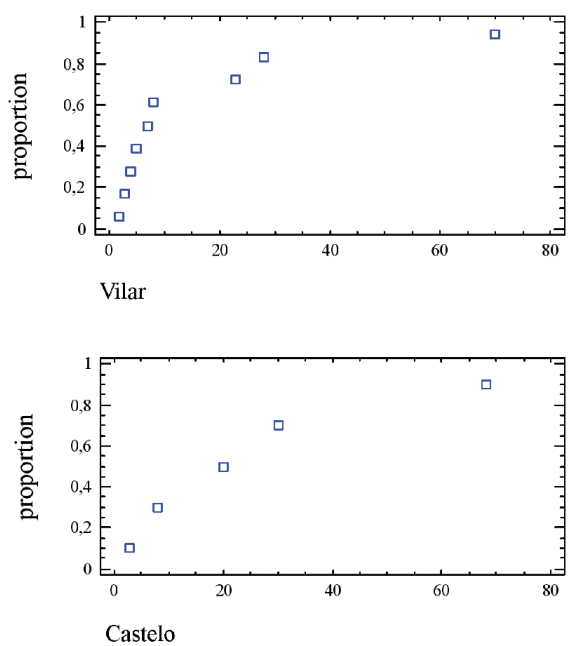

of the inner growth with their diversification (both basal and side-wall types). The nolinear trend appears when the inner diversification (cavities developed into the tafoni) reaches a threshold value. This trend is clear for the intermediate conditions of growth in the two samples. The identification of steps in the biggest forms suggests several differentiated phases of development; the depth progress in time decreases the inner diversification and involves behaviour towards stable conditions in the basal or side-walls forms.
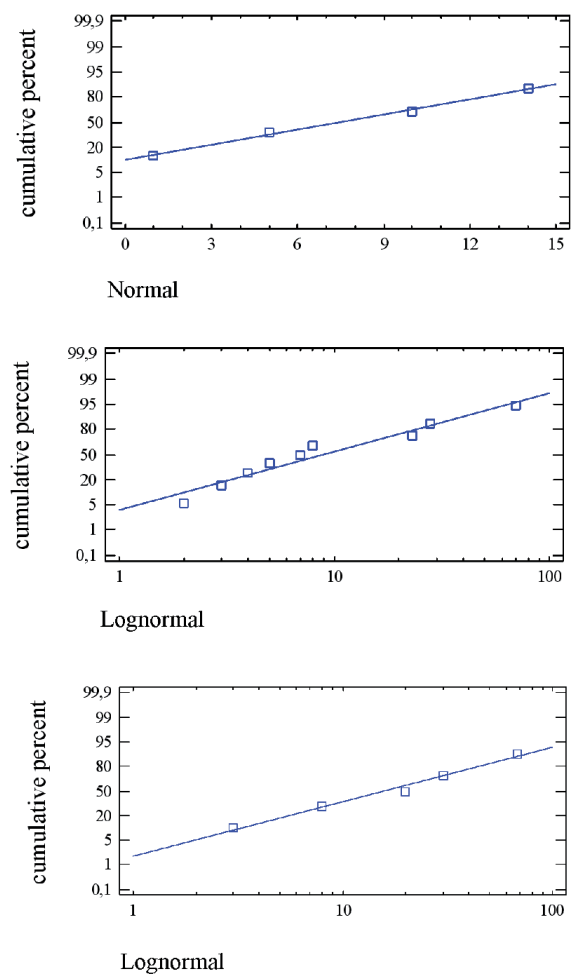

Figure 4. Development trends of the basal types. 
QUANTIL PLOT (Growth)
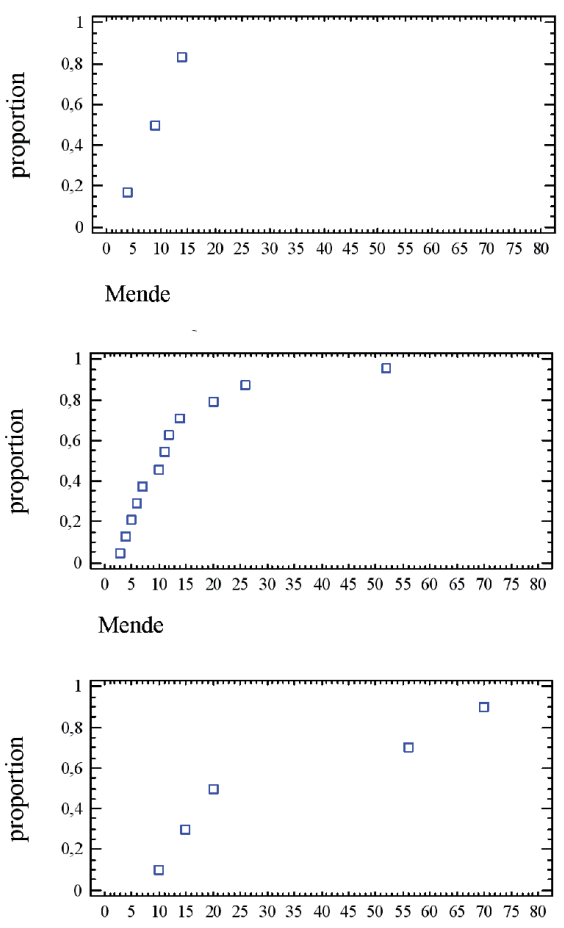

Castelo
PROBABILITY PLOT (Trend)

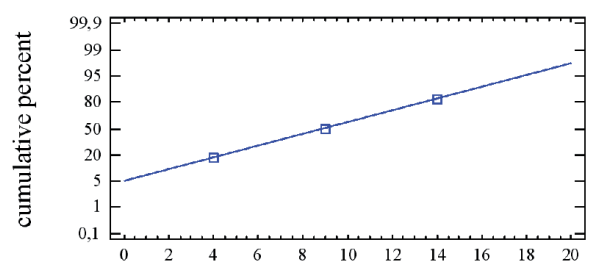

Normal
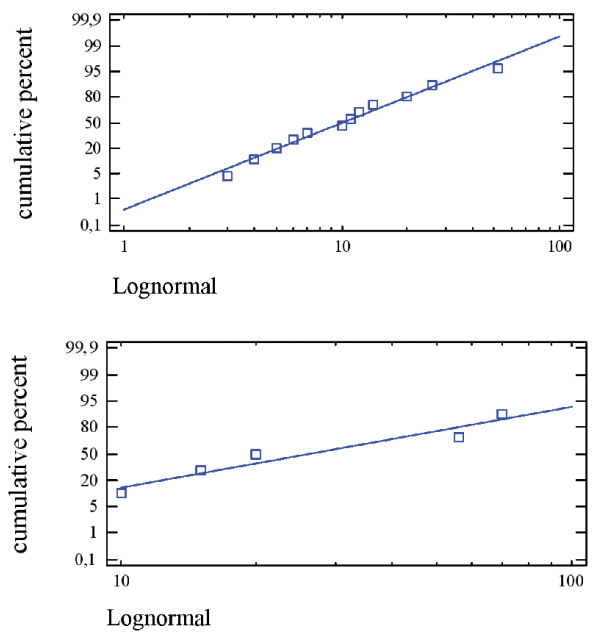

Figure 5. Development trends of the side-wall types.

The acknowledged categories have a meaning within the context of a polyphasic morphogenesis (global scale), a framework in which the phenomena connecting these categories to the landscape where they occur (local scale) is analysed.

\section{CONCLUSION}

Tafoni's existence allows the differentiation of rock volumes by acting as propaga- tion nodes in precise magnitudes, through its own form or through limiting discontinuities. Taking into account the results from the dimensional analysis and the study of growth trends, this phenomenon develops complexity through self-organisation. It represents an irreversible condition on different scales.

The results of this study show a relational guideline between constant and changeable states, in the sense of an ability to face 
changes regarding a previous design. Morphological diversity highlights unstable and stable conditions. The maintenance of linear trends in the forms development reveals selfreinforcing feedbacks. Thresholds between development stages involve changes of the morphology related to self-limitation feedbacks.

\section{REFERENCES}

DE UÑA ÁlVAREZ, E. (2004). Tafoni en rocas graníticas. Primera valoración estadística sobre tasas de desarrollo en el macizo de Ourense (Galicia, NW de la Península Ibérica). Cadernos do Laboratorio Xeolóxico de Laxe, 29, 265-289.

DE UÑA ÁLVAREZ, E. and VIDAL ROMANÍ, J. R. (2006). Estructura y forma: Estudio experimental en cacholas (ta- foni) de Galicia (NW Peninsular). Geomorfología y Territorio - IX Reunión Nacional de Geomorfología, Serie Cursos y Congresos USC, 171, 785-793.

DE UÑA ÁLVAREZ, E. and VIDAL ROMANÍ, J. R. (2008). Some minor features (tafoni, cavernous forms) in the granite terrains of Los Riojanos (Pampa de Achala, Sierra Grande de Córdoba, República Argentina). Geometric and morphologic properties. Cadernos do Laboratorio Xeolóxico de Laxe, 33, 83100.

TWIDALE, C. R. and VIDAL ROMANÍ, J. R. (2005). Landforms and Geology of Granite Terrains. London, Balkema, $351 \mathrm{p}$.

TWIDALE, C. R. and BOURNE, J. A. (2008). Caves in granitic rocks: Types, terminology and origin. Cadernos do Laboratorio Xeolóxico de Laxe, 33, 35-57. 